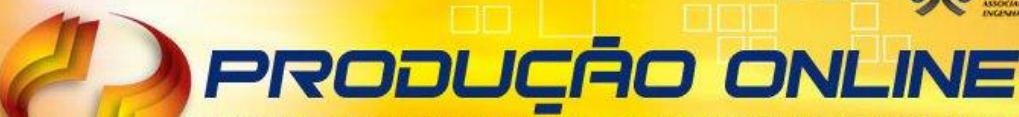 \\ REVISTA CIENTIFICA ELETRÔNICA DE ENGENHARIA DE PRODUÇÃO
} ISSN 1676-1901

\section{UMA DINÂMICA PARA O ENSINO DA MATRIZ PRODUTO-PROCESSO: ROTEIRO E APLICAÇÃO}

\section{A HANDS-ON ACTIVITY FOR TEACHING PRODUCT-PROCESS MATRIX: ROADMAP AND APPLICATION}

\author{
Luciano Costa Santos* E-mail: luciano@ct.ufpb.br \\ Leonardo de Miranda Arnaud* E-mail: leoarnaud@gmail.com \\ Jéssica Bezerril Dutra *E-mail: jessicabezerril@hotmail.com \\ *Universidade Federal da Paraíba, João Pessoa, PB
}

Resumo: A matriz produto-processo é um conhecido modelo conceitual proposto por Hayes e Wheelwright (1979) que é comumente utilizado para a identificação dos tipos de processos produtivos e para a análise do alinhamento desses processos com os produtos de uma empresa. Para fins didáticos, a matriz auxilia os graduandos das séries iniciais do curso de Engenharia de Produção a compreender a lógica dos sistemas de produção, fundamentando conhecimentos que serão essenciais para diversas disciplinas do curso. Considerando o alto grau de abstração dos conceitos subjacentes à matriz produto-processo, este artigo apresenta uma forma de facilitar a aprendizagem dos mesmos por meio da aplicação de uma dinâmica de ensino que utiliza a filosofia de aprendizagem ativa como eixo metodológico. A dinâmica proposta utiliza fichas coloridas de plástico e tubos de PVC como materiais principais, diferenciando-se da proposta original de Penlesky e Treleven (2005). Além de apresentar uma dinâmica extremamente simples, o que encoraja sua aplicação em sala de aula, outra contribuição do presente artigo é a definição de um roteiro completo para a realização da atividade. Este roteiro prevê a montagem de produtos fictícios em cenários de personalização e padronização para a comparação de dois tipos de processos da matriz produtoprocesso, produção por tarefa (job shop) e produção em massa (linha de montagem). O sucesso na utilização da dinâmica foi comprovado após sua aplicação em duas turmas de um curso de Engenharia de Produção, confirmado por meio das respostas positivas obtidas em um questionário de avaliação.

Palavras-chave: Matriz produto-processo. Dinâmicas de ensino. Aprendizagem ativa.

Abstract: The product-process matrix is a well-known framework proposed by Hayes and Wheelwright (1979) that is commonly used to identify processes types and to analyze the alignment of these processes with the products of a company. For didactic purposes, the matrix helps undergraduates beginners from Production Engineering to understand the logic of production systems, providing knowledge that will be essential for various course subjects. Considering the high level of abstraction of the concepts underlying the product-process matrix, this paper presents a way to facilitate the learning of them through the application of a hands-on activity which relies on the active learning philosophy. The proposed dynamic uses colored plastic sheets and PVC pipes as main materials, differing from the original proposal of Penlesky and Treleven (2005). In addition to presenting an extremely simple exercise, which encourages its application in the classroom, another contribution of this paper is to define a complete roadmap for conducting the activity. This roadmap describes the assembly of fictitious products in customization and standardization scenarios for the comparison of two processes types of product-process matrix, job shop and assembly line. The activity revealed very successful after its application to two groups of Production Engineering undergraduates, confirmed with positive feedback from the students surveyed.

Keywords: Product-process matrix. Teaching activities. Active learning.

Revista Produção Online, Florianópolis, SC, v.14, n. 3, p. 1129-1150, jul./set. 2014. 


\section{INTRODUÇÃO}

A mudança do perfil dos estudantes de graduação tem forçado a constante evolução no ensino de Engenharia de Produção. Nos dias atuais, os graduandos têm acesso a uma ampla diversidade de informações e a diferentes tecnologias para sua obtenção. Com esse movimento, as aulas expositivas tradicionais têm sua relevância reduzida, dado que grande parte das informações que os alunos adquirem em aulas desse tipo podem ser obtidas de outras maneiras. Por outro lado, quando os professores percebem que já não recebem a mesma atenção de outrora, procuram outras formas para "chamar a atenção" de seus alunos.

Outro elemento que tem exercido pressão para a mudança nos métodos tradicionais de ensino é o mercado de trabalho. O panorama competitivo das empresas de hoje requer profissionais que possuam competências que nem sempre são desenvolvidas nas universidades. Não é raro encontrar empresas que fornecem treinamento de assuntos que os profissionais já deveriam ter aprendido na universidade. Também não é raro encontrar treinadores de empresas que criam aulas mais envolventes que aquelas encontradas nas universidades.

Por causa desses fatores, o modelo tradicional em que o estudante assiste passivamente à aula tem dado lugar àquilo que Auster e Wylie (2006) chamam de aprendizagem ativa. Segundo esses autores, a aprendizagem ativa é caracterizada pelo forte envolvimento dos estudantes no desenvolvimento de seu próprio conhecimento, que normalmente participam de simulações da prática e projetos para a solução de problemas do mundo real.

$\mathrm{Na}$ Engenharia de Produção a transição para o modelo de aprendizagem ativa tem acontecido com frequência na aplicação de dinâmicas criativas de ensino. Essas dinâmicas geralmente simulam o comportamento de sistemas produtivos e proporcionam aos estudantes a possibilidade de experimentar situações que habitualmente são descritas (mas não experimentadas) em aulas expositivas.

Tomando como base a filosofia de aprendizagem ativa, este artigo tem o objetivo de descrever uma dinâmica de ensino que permite compreender a lógica da matriz produto-processo, um conhecido framework proposto por Hayes e Wheelwright (1979) que fundamenta a classificação de sistemas de produção e auxilia na compreensão da adequação entre os tipos de processos produtivos e as Revista Produção Online, Florianópolis, SC, v.14, n. 3, p. 1129-1150, jul./set. 2014. 
características dos produtos de uma empresa. A dinâmica relatada neste artigo foi inicialmente publicada por Penlesky e Treleven (2005) e sofreu adaptações para ser aplicada em duas turmas da disciplina "Sistemas de Produção" de um curso de graduação em Engenharia de Produção de uma universidade federal.

Inicialmente, o artigo aborda conceitos subjacentes à filosofia de aprendizagem ativa e também fornece exemplos de dinâmicas de ensino na área de gestão da produção. Em seguida, é apresentada a matriz produto-processo, objeto de aprendizagem da dinâmica. Posteriormente, o artigo descreve a dinâmica proposta e sua metodologia de aplicação. Depois, o texto prossegue com a discussão dos resultados da aplicação e se encerra com as considerações finais do trabalho.

\section{DINÂMICAS DE ENSINO-APRENDIZAGEM}

As metodologias de ensino têm evoluído ao longo dos anos em direção à aprendizagem por meio do envolvimento direto dos estudantes com os conteúdos ministrados (ZEPKE; LEACH, 2010). Em busca dessa evolução, surge o conceito de aprendizagem ativa, definida de uma forma simplificada por Bonwell e Eison (1991, p. 2) como uma abordagem que "envolve os estudantes em fazer coisas e pensar sobre aquilo que estão fazendo". A aprendizagem ativa é caracterizada pelo grande envolvimento dos estudantes no processo de aprendizagem (HERIOT et al., 2008; PRINCE, 2004), melhorando a capacidade dos mesmos em converter conceitos teóricos em conhecimento prático.

A aprendizagem ativa é um termo amplo e pode se manifestar de várias formas. De acordo com Snider e Balakrishnan (2013), a aprendizagem experiencial é uma forma mais intensa de aprendizagem ativa, já que os estudantes têm a oportunidade de aprender por meio da experiência direta com o objeto de estudo. A figura 1 mostra a visão dos autores em relação aos diferentes modos de aprendizagem ativa.

Em relação ao conceito de aprendizagem experiencial, Itin (1999) faz uma ressalva importante ao diferenciá-la da educação experiencial. Enquanto a aprendizagem experiencial pode ocorrer independentemente da instrução formal, a 
educação experiencial ressalta o papel do professor ao induzir experiências relacionadas ao objeto de estudo.

Figura 1 - Formas de aprendizagem ativa

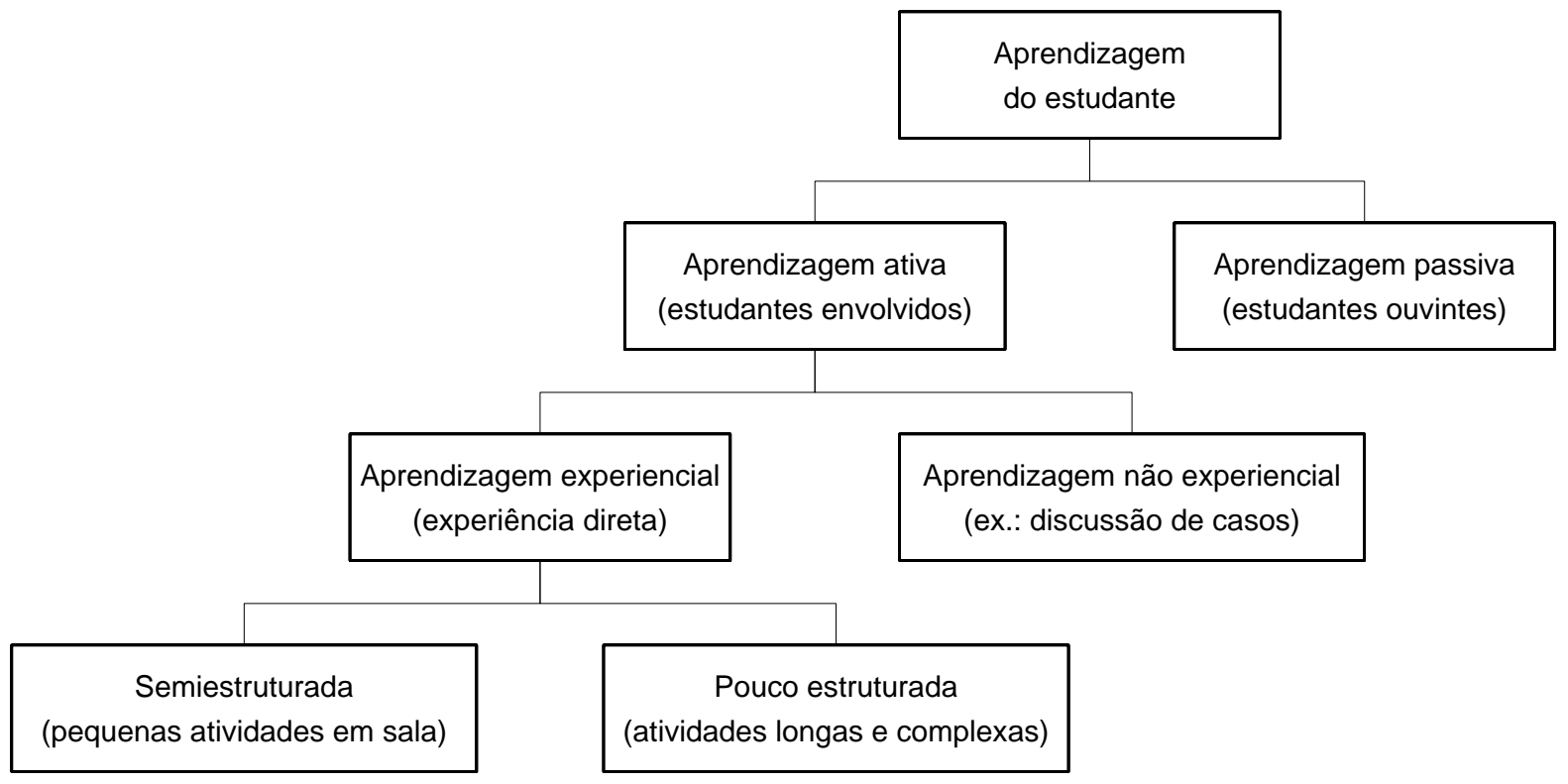

Fonte: Snider e Balakrishnan (2013)

Atualmente, a educação experiencial tem se concretizado na sala de aula por meio de dinâmicas interativas de aprendizagem. A aplicação de dinâmicas de ensino-aprendizagem no âmbito da Engenharia de Produção tem sido relatada com frequência em simulações e jogos sobre conceitos da área de gestão da produção. Có, Có e Merigueti (2008), por exemplo, desenvolveram um jogo didático com cartas de baralho para o ensino do conceito de heyjunka, uma das principais práticas da manufatura enxuta. Lage Junior (2008), por sua vez, utilizou bloquinhos de montagem LEGO ${ }^{\circledR}$ para explicitar as diferenças entre manufatura e remanufatura em ambientes de programação com o sistema MRP.

Em publicações internacionais também é possível identificar dinâmicas que utilizam diferentes tipos de materiais, como por exemplo, jogos de dados (LAMBRECHT et al., 2012), aviões de papel (BILLINGTON, 2004) ou conexões de PVC (SANTOS; GOHR; VIEIRA JUNIOR, 2012). Em geral, essas dinâmicas requerem a participação do estudante em simulações que reproduzem, por analogia, ambientes e processos de produção. Esse tipo de simulação é denominada por 
Smeds (2003) de simulação social, que se diferencia da simulação computacional por ser caracterizada por interações humanas entre os participantes.

$\mathrm{Na}$ área de gestão da produção é muito comum encontrar na literatura dinâmicas que enfatizam conceitos que os alunos têm acesso somente após as fases iniciais do curso, como balanceamento de linhas de montagem (AMMAR; WRIGHT, 1999) ou manufatura enxuta (OZELKAN; GALAMBOSI, 2009). Dinâmicas que abordam conceitos aprendidos no início do curso são mais escassas na literatura. Escassas, porém não menos importantes, uma vez que a utilização de atividades de aprendizagem ativa pode estimular estudantes em fases iniciais e ajudar a consolidar conceitos que servirão de base para aquilo que aprenderão posteriormente.

A matriz produto-processo tem sido abordada na disciplina "Sistemas de Produção" do curso no qual foi aplicada a dinâmica relatada neste artigo. Esta disciplina é ministrada no segundo semestre da estrutura curricular e introduz conceitos que são fundamentais para diversas disciplinas do curso.

\section{MATRIZ PRODUTO-PROCESSO}

A matriz produto-processo foi proposta por Hayes e Wheelwright (1979) com o objetivo de correlacionar as estruturas dos processos de produção com diferentes estruturas de produto, tal como mostra a figura 2. Para didáticos, a matriz auxilia na identificação dos tipos de processos produtivos e do seu alinhamento aos produtos de uma empresa. Uma característica da matriz produto-processo é que ela assume que um desempenho competitivo superior é atingindo quando um sistema de produção está situado na diagonal da matriz, ou seja, parte-se do princípio que existe uma combinação ótima entre produto e processo.

A matriz produto-processo propõe quatro tipos básicos de processos: produção por tarefa (job shop), produção em lotes, produção em massa (linhas de montagem) e produção em processos contínuos. Essa classificação é coerente com outras classificações de sistemas de produção, como por exemplo, a matriz volumevariedade, proposta inicialmente por Hill (1994) e disseminada por livros-textos populares como os de Slack, Chambers e Johnston (2002) e Krajewsky, Ritzman e 
Malhotra (2009). A matriz volume-variedade ainda acrescenta a produção por projeto, que faz parte da maioria dos modelos de classificação de sistemas de produção.

Figura 2 - Matriz produto-processo

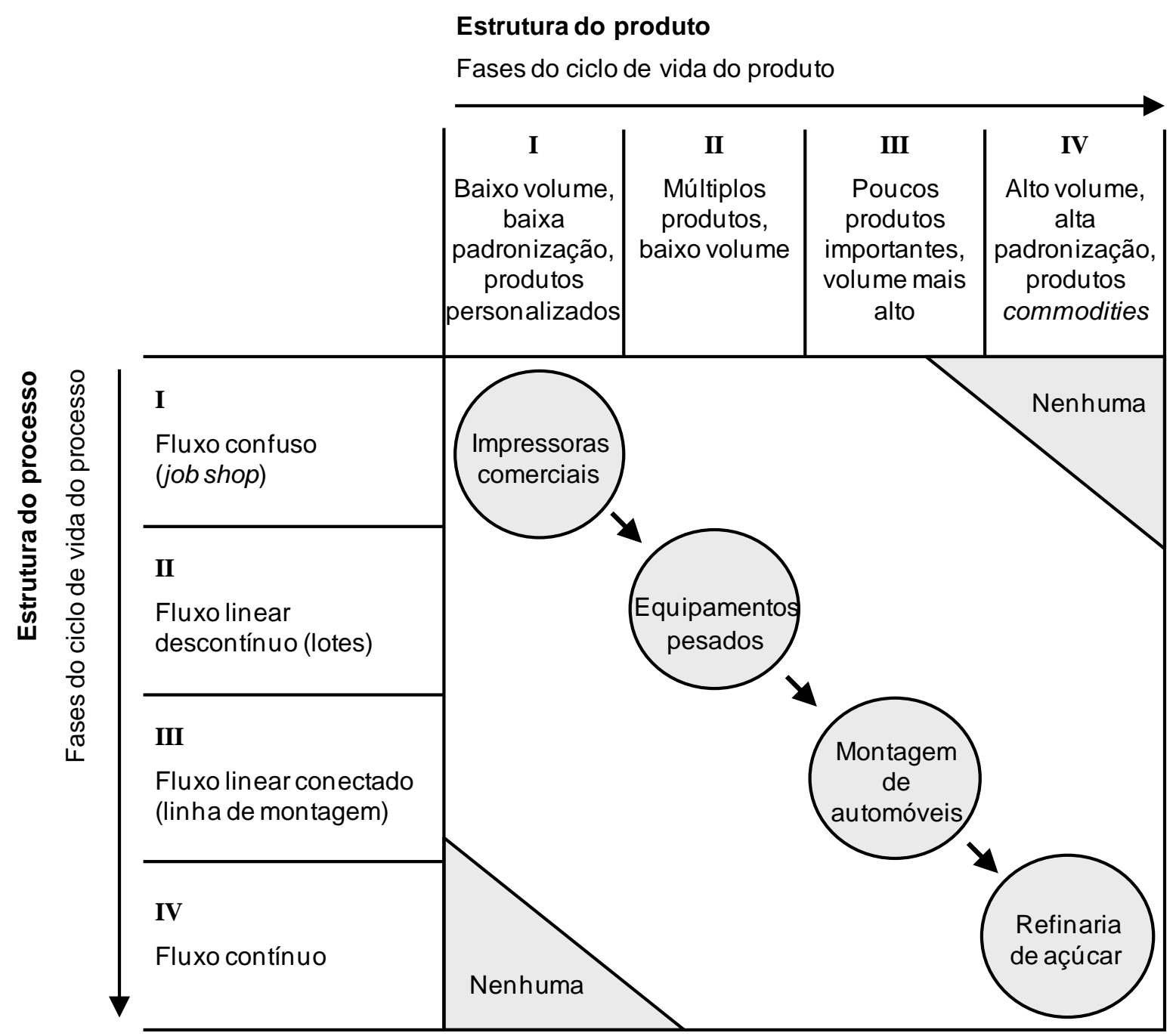

Fonte: Hayes e Wheelwright (1979)

Embora a matriz produto-processo não aborde a produção por projeto, sendo muitas vezes vista como um modelo incompleto, ela contribuiu de forma decisiva para a noção de que existem processos mais adequados para certas combinações de produtos. Isso reflete diretamente na definição dos critérios de escolha do processo produtivo e no posicionamento estratégico de um sistema de produção. Por esse motivo, a matriz produto-processo continua sendo refinada e permanece Revista Produção Online, Florianópolis, SC, v.14, n. 3, p. 1129-1150, jul./set. 2014. 
como um objeto de pesquisa relevante para a área (HELKIÖ; TENHIÄLÄ, 2013; AHMAD; SCHROEDER, 2002). De igual relevância é a abordagem desse assunto no ensino de graduação em Engenharia de Produção, pois ajuda a desenvolver no graduando o pensamento crítico sobre os sistemas de produção.

\section{METODOLOGIA}

A atividade proposta tem o objetivo de comparar dois tipos de processos da matriz produto-processo, produção por tarefa (job shop) e produção em massa (linha de montagem), e sua adequação para dois tipos de produtos, personalizados e padronizados. Para isso, é simulada a montagem de 12 produtos fictícios, que são formados a partir do empilhamento de fichas coloridas de plástico, tal como mostram as fotografias da figura 3 .

Figura 3 - Materiais utilizados
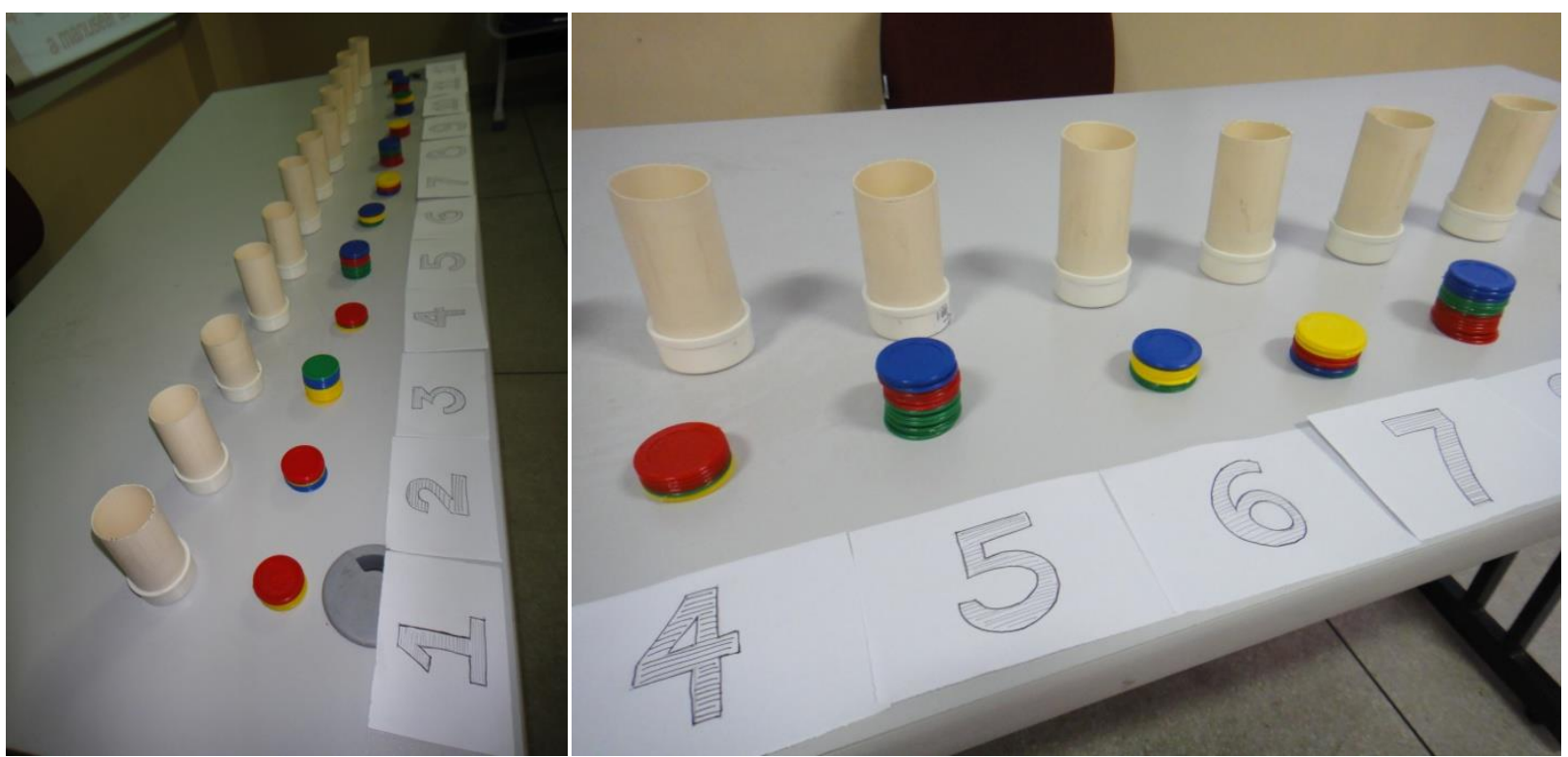

Fonte: Elaborado pelo autores

Cada pilha de fichas representa um produto que possui um roteiro de montagem específico. Os componentes dos produtos se diferenciam pela cor das fichas (amarelas, azuis, verdes ou vermelhas), sendo que cada componente é "fabricado" em um departamento diferente. Cada departamento é situado em um canto da sala, forçando a movimentação de produtos em processamento.

Revista Produção Online, Florianópolis, SC, v.14, n. 3, p. 1129-1150, jul./set. 2014. 
Durante a produção os operadores dos departamentos colocam as fichas em pedaços de tubos de PVC de diâmetro proporcional às mesmas. Esses tubos são abertos em uma extremidade e fechados com um tampão (cap) na outra. A ordem em que as fichas são colocadas é definida pelo roteiro de produção. Neste caso, os tubos funcionam tanto como equipamentos de movimentação que transportam produtos semiacabados de um departamento para outro, quanto como plataformas que auxiliam na formação do produto.

Quando o roteiro está concluído, o produto é entregue ao virar o tubo para baixo no local de recebimento. Ao retirar cuidadosamente o tubo, a natureza do produto é revelada pela combinação de cores de cada pilha de fichas.

Para um maior detalhamento, a metodologia proposta pode ser dividida em duas fases, preparação e execução, apresentadas a seguir.

\subsection{Preparação}

Uma das vantagens da dinâmica proposta é que os materiais necessários para a aplicação são simples e de baixo custo. Embora a dinâmica seja adaptável para diferentes aplicações, sugere-se uma lista inicial:

- 48 fichas vermelhas, 36 fichas azuis, 36 fichas amarelas e 36 fichas verdes.

- 12 pedaços de tubo de PVC de aproximadamente $8 \mathrm{~cm}$ de comprimento. $\mathrm{O}$ diâmetro dos tubos deve ter uma dimensão que possa acomodar as fichas facilmente, porém sem folgas excessivas. Nesta aplicação foram usados tubos de $40 \mathrm{~mm}$ de diâmetro.

- 12 tampões (cap) para serem colados nas extremidades dos tubos.

- 4 folhas de cartolina colorida: uma vermelha, uma azul, uma amarela e outra verde. Essas folhas são afixadas com fita crepe na parede de cada departamento para sinalizar visualmente que tipo de ficha ele irá produzir. Alternativamente, poderão ser usados outros materiais coloridos para marcar os departamentos.

- 24 folhas impressas com os roteiros de produção: 12 com roteiros de produtos personalizados e 12 com roteiros de produtos padronizados. As Revista Produção Online, Florianópolis, SC, v.14, n. 3, p. 1129-1150, jul./set. 2014. 
folhas de roteiro que foram utilizadas são apresentadas nos Anexos I e II. A quantidade de fichas foi calculada em função do total de peças que os roteiros iriam demandar.

Na proposta original de Penlesky e Treleven (2005) foram utilizadas moedas ao invés de fichas de plástico e essas moedas eram armazenadas em copos ou pequenas caixas. Optou-se por adaptar a dinâmica com fichas coloridas pelo menor custo e pelo efeito visual dos diferentes componentes do produto. A armazenagem nos tubos também deu mais praticidade à aplicação, tanto no processo de montagem do produto quanto na entrega do mesmo nas áreas de recebimento.

Antes de simular o processo de montagem, o local de realização da atividade deve ser organizado. Se for uma sala de aula, é importante retirar as cadeiras do centro da sala para evitar a obstrução das áreas de movimentação. Uma sugestão viável é formar um círculo com as cadeiras.

São montadas duas configurações de layout, de acordo com a figura 4. Em um primeiro momento é montado um layout funcional para o processo job shop. Posteriormente, adota-se a configuração de um layout linear para a linha de montagem. A mudança de configuração se dá simplesmente pela troca das folhas de cartolina colorida que demarcam os departamentos. A área de recebimento poderá ser a própria mesa do professor que deverá ter sinalizações para os locais de cada produto (pedaços de papel são suficientes).

Aparentemente, a figura 4 não demonstra que um layout é funcional e o outro linear. Porém, ao verificar o roteiro dos produtos padronizados no Anexo II, é possível perceber que a configuração dos departamentos do layout linear compõe uma linha de montagem em formato de "U". Naturalmente, o layout linear foi concebido para maximizar a eficiência na produção de produtos padronizados. Já o layout funcional procura garantir a flexibilidade necessária para a produção de uma variedade de produtos personalizados.

Após a organização da sala, é necessário distribuir as funções dos participantes. A atividade requer 4 operadores dos departamentos e 12 movimentadores, completando um total de 16 trabalhadores na "fábrica". Se a turma tiver mais que 16 alunos, sugere-se revezar as funções para que todos participem. Se a turma tiver menos que 16 alunos, é necessário colocar alguns alunos para 
exercerem a função de 2 movimentadores em momentos distintos. A atividade também requer um cronometrista e um gerente de PCP para liberar as ordens de produção. Essas funções poderão ser exercidas pelo próprio professor.

Figura 4 - Layouts sugeridos

Layout funcional para job shop

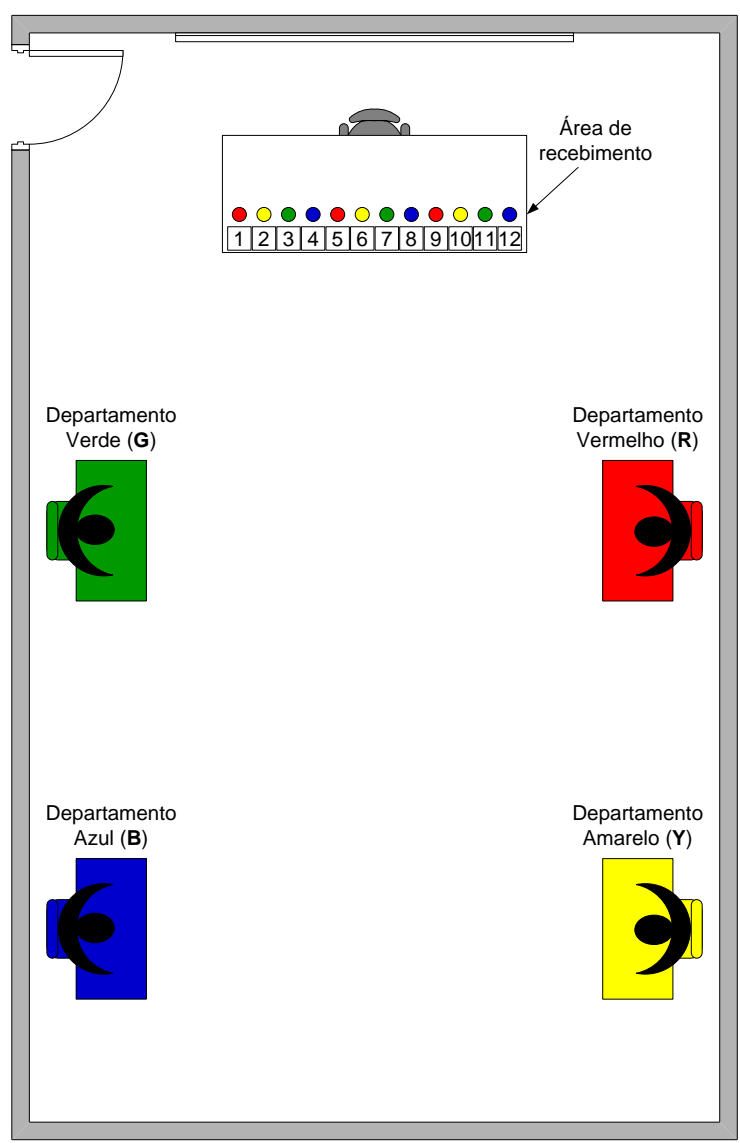

\section{Layout linear para linha de montagem}

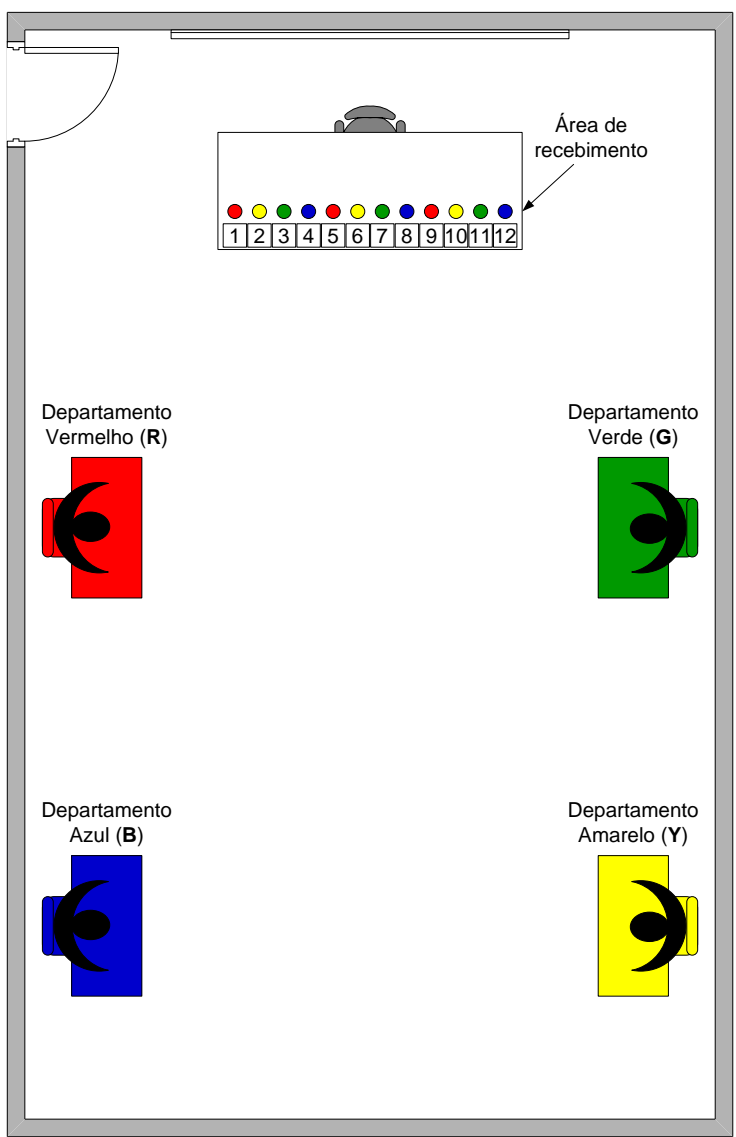

Fonte: Elaborado pelo autores

\subsection{Execução}

De uma forma geral, a execução da atividade acontece da seguinte forma:

- Os operadores se dirigem para seus departamentos munidos do estoque de fichas de mesma cor.

- Os movimentadores formam uma fila na porta da sala, na sequência relativa ao número da ordem de produção ou tarefa (Anexos I e II) que cada movimentador fica responsável. Por exemplo, o primeiro da fila é responsável pela Tarefa 1 e o último da fila é responsável pela Tarefa 12. Revista Produção Online, Florianópolis, SC, v.14, n. 3, p. 1129-1150, jul./set. 2014. 
- Cada movimentador recebe um tubo (recipiente) e uma folha de roteiro e localiza a ordem de produção que vai executar. Para a codificação dos roteiros, cada departamento foi identificado com a inicial do nome da cor em inglês: R para o departamento vermelho (red), B para o azul (blue), Y para o amarelo (yellow) e $G$ para o verde (green). Optou-se pelas iniciais em inglês, pois os nomes em português têm iniciais iguais ( $V, V, A, A)$.

- O gerente de PCP (professor) se posiciona na área de recebimento e libera as ordens de produção. Todas as ordens de produção devem ser liberadas ao mesmo tempo. O sequenciamento segue a regra FIFO (first in, first out) na execução das Tarefas de 1 a 12.

- O cronometrista dispara o cronômetro no momento da liberação de ordens de produção.

- O processo começa com os 12 movimentadores saindo ao mesmo tempo. Embora estejam em fila para evitar tumultuar o ambiente, movimentadores que utilizarão departamentos diferentes na primeira operação poderão sair em paralelo. As fichas devem ser recolhidas pelos movimentadores na sequência e na quantidade listada no roteiro de produção. Por exemplo, quando a Tarefa 1 do Anexo I é realizada em layout funcional, o movimentador se dirige diretamente ao departamento vermelho $(R)$ e pede 3 fichas. Em seguida, vai para o departamento amarelo e pede 6 fichas. Depois segue para a área de recebimento e deposita as fichas no local virando o tubo para baixo, retirando-o cuidadosamente e formando a pilha de fichas que constitui o produto. É importante observar que os movimentadores não tocam nas fichas, pois somente os operadores dos departamentos estão autorizados a manuseá-las.

- Quando o último produto chega na área de recebimento, o cronometrista interrompe o cronômetro e registra o tempo. Este tempo é chamado de makespan, que corresponde ao intervalo que decorre entre a liberação das ordens e o recebimento do último produto.

A atividade é executada quatro vezes, uma para cada cenário. Coforme apresenta o quadro 1, os cenários são definidos em função da combinação dos dois tipos de processos com os dois tipos de produtos.

Revista Produção Online, Florianópolis, SC, v.14, n. 3, p. 1129-1150, jul./set. 2014. 
Ao término da execução de cada cenário, as fichas são devolvidas para os estoques de seus respectivos departamentos, os movimentadores são reorganizados, os layouts são trocados e o processo recomeça.

Quadro 1 - Cenários para a execução da dinâmica

\begin{tabular}{|c|c|c|c|}
\hline & \multicolumn{2}{|c|}{ Tipos de produto } \\
\hline & & Personalizados & Padronizados \\
\hline \multirow{2}{*}{ 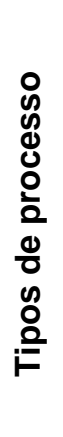 } & Job shop & $\begin{array}{l}\text { Cenário } 1 \\
\text { - Diferentes roteiros } \\
\text { de produção } \\
\text { - Sequência definida } \\
\text { pelo roteiro }\end{array}$ & $\begin{array}{l}\text { Cenário } 3 \\
\text { - Único roteiro de } \\
\text { produção } \\
\text { - Sequência definida } \\
\text { pelo roteiro }\end{array}$ \\
\hline & $\begin{array}{l}\text { Linha de } \\
\text { montagem }\end{array}$ & $\begin{array}{l}\text { Cenário } 2 \\
\text { - Diferentes roteiros } \\
\text { de produção } \\
\text { - Sequência definida } \\
\text { pela linha }\end{array}$ & $\begin{array}{l}\text { Cenário } 4 \\
\text { - Único roteiro de } \\
\text { produção } \\
\text { - Sequência definida } \\
\text { pela linha }\end{array}$ \\
\hline
\end{tabular}

Fonte: Elaborado pelos autores

Para os Cenários 1 e 2, existirá um roteiro específico para cada produto, uma vez que os mesmos são personalizados e demandam recursos diferentes. A diferença entre os dois cenários está no layout. No Cenário 1, o layout permite que os movimentadores visitem somente os departamentos dos quais eles precisam de fichas, respeitando a ordem e a quantidade estabelecida no roteiro, mas tendo a flexibilidade suficiente para determinar o fluxo físico de movimentação. Já no Cenário 2, o fluxo é determinado pela linha que apresenta o formato de "U" na sequência R-B-Y-G dos departamentos (ver figura 4). Neste caso, os movimentadores devem visitar todos os departamentos na sequência determinada pela linha. Quando não houver ficha a recolher, o operador dará um visto na folha de roteiro.

Quando usada para produtos personalizados, a configuração em linha pode requerer que os movimentadores deem várias voltas na linha para completar o produto na ordem certa. A figura 5 mostra um exemplo da movimentação que ocorre na execução da Tarefa 7 do roteiro de produtos personalizados (Anexo I).

Um aspecto a destacar é que a formação de filas em determinados departamentos é uma consequência natural do processo, uma vez que todos os movimentadores saem logo após a liberação de ordens de produção e não podem Revista Produção Online, Florianópolis, SC, v.14, n. 3, p. 1129-1150, jul./set. 2014. 
"pular" o ordenamento das operações. Esse fenômeno reproduz o que acontece no chão-de-fábrica e é análogo ao estoque em processo que está esperando uma operação.

Figura 5 - Fluxo de movimentação da Tarefa 7 nos Cenários 1 e 2

Cenário 1 - Job shop

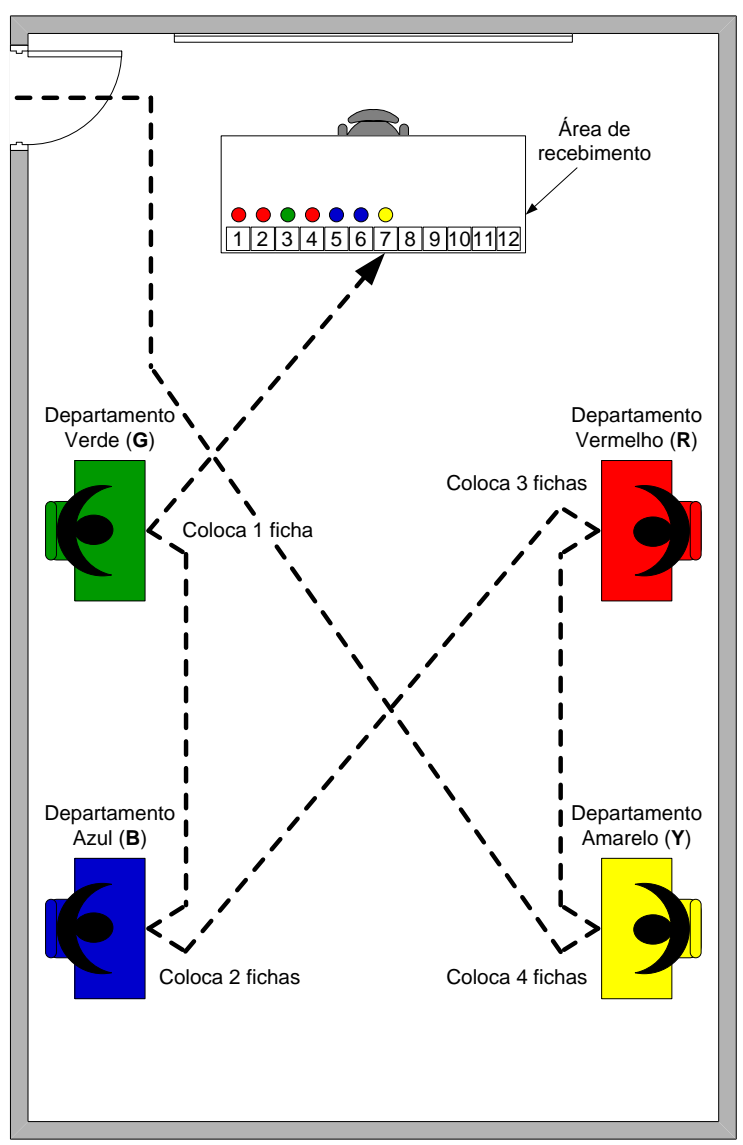

Cenário 2 - Linha de montagem

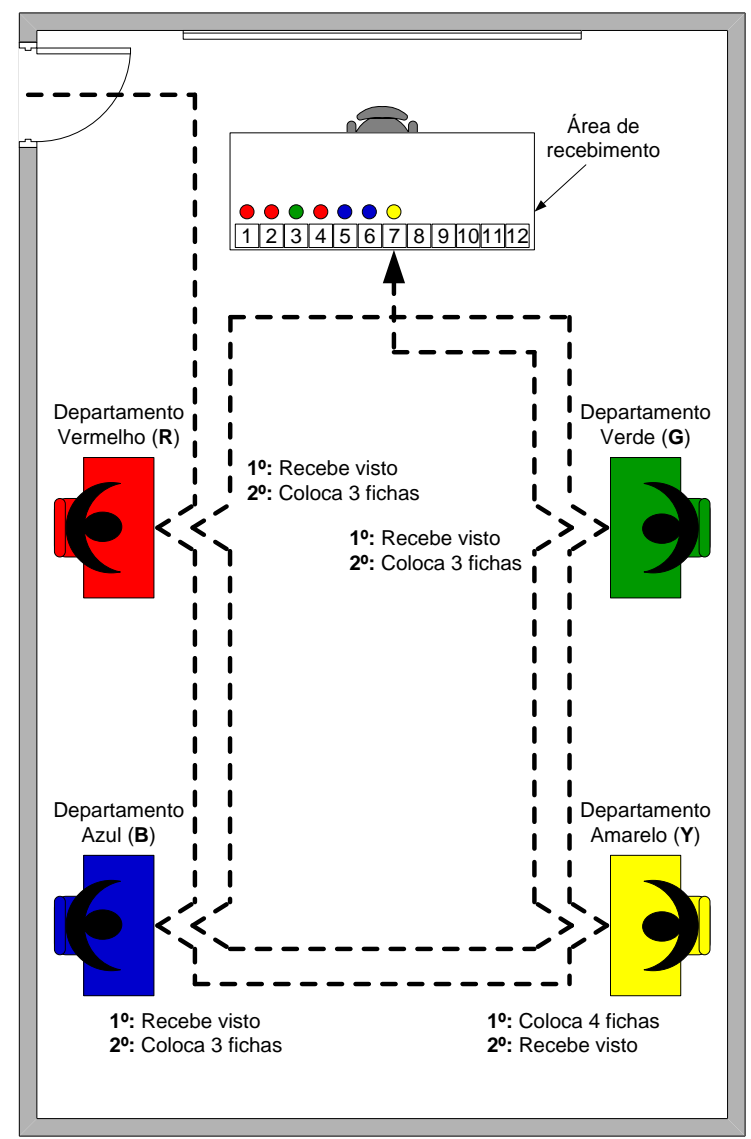

Fonte: Elaborado pelo autores

Ao comparar a movimentação que ocorre no Cenário $1 \mathrm{com}$ aquela que ocorre no Cenário 2, já é possível perceber uma adequação maior do processo job shop para situações em que se têm produtos personalizados (Cenário 1), confirmando aquilo que preconiza a matriz produto-processo. O Cenário 2 gera mais movimentações desnecessárias e provavelmente gerará um maior makespan.

Após a realização dos Cenários 1 e 2, os roteiros de produção são trocados. Os novos roteiros preveem a montagem de 12 produtos iguais (padronizados), com a mesma sequência de operações e a mesma quantidade de peças a recolher. 
Com os roteiros de produtos padronizados devidamente distribuídos, o Cenário 3 é executado no layout para processos job shop. Em seguida, o layout é trocado novamente e o Cenário 4 é executado. A figura 6 apresenta o fluxo físico da movimentação nos Cenários 3 e 4, para produtos padronizados (Anexo II).

Observa-se na figura 6 que o layout linear do Cenário 4 foi projetado para atender exclusivamente $o$ roteiro de produção dos produtos padronizados, formando uma linha de montagem em "U". Assim, ele confere uma maior eficiência ao processo e confirma a lógica da matriz produto-processo, que defende uma adequação maior das linhas de produção quando se pretende produzir produtos padronizados. A comparação dos makespans dos Cenários 3 e 4 também tende a comprovar uma maior eficiência do Cenário 4.

Ao final da execução dos quatro cenários, o professor deve fomentar a discussão em sala de aula comparando o que foi observado em termos de movimentação do fluxo e em função dos makespans registrados. Além da comparação vertical dos makespans (C1 $\times$ C2 e C3 x C4), também pode ser útil uma análise horizontal dos makespans ( $1 \times 1 \times \mathrm{C} 3$ e $\mathrm{C} 2 \times \mathrm{C} 4)$, explorando a questão pela lógica inversa: "Quais tipos de produtos são mais adequados para o processo por tarefa (job shop)? E para a produção em linhas de montagem?"

Durante a discussão em aula, o professor deve retomar os conceitos subjacentes à matriz produto-processo, utilizando exemplos daquilo que ocorreu na dinâmica e tornando mais tangível a exposição teórica. Com a intervenção do professor, a experiência se consolida em aprendizagem, alcançando os objetivos da atividade proposta. 
Figura 6 - Fluxo de movimentação nos Cenários 3 e 4

Cenário 3 - Job shop

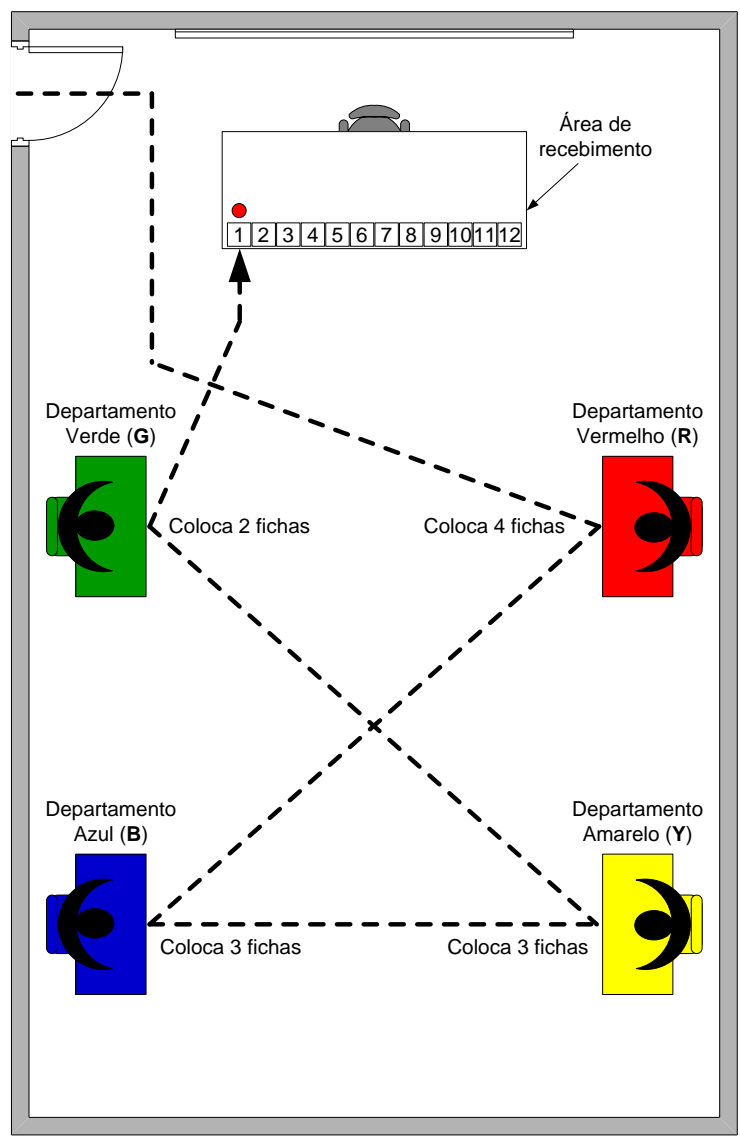

Cenário 4 - Linha de montagem

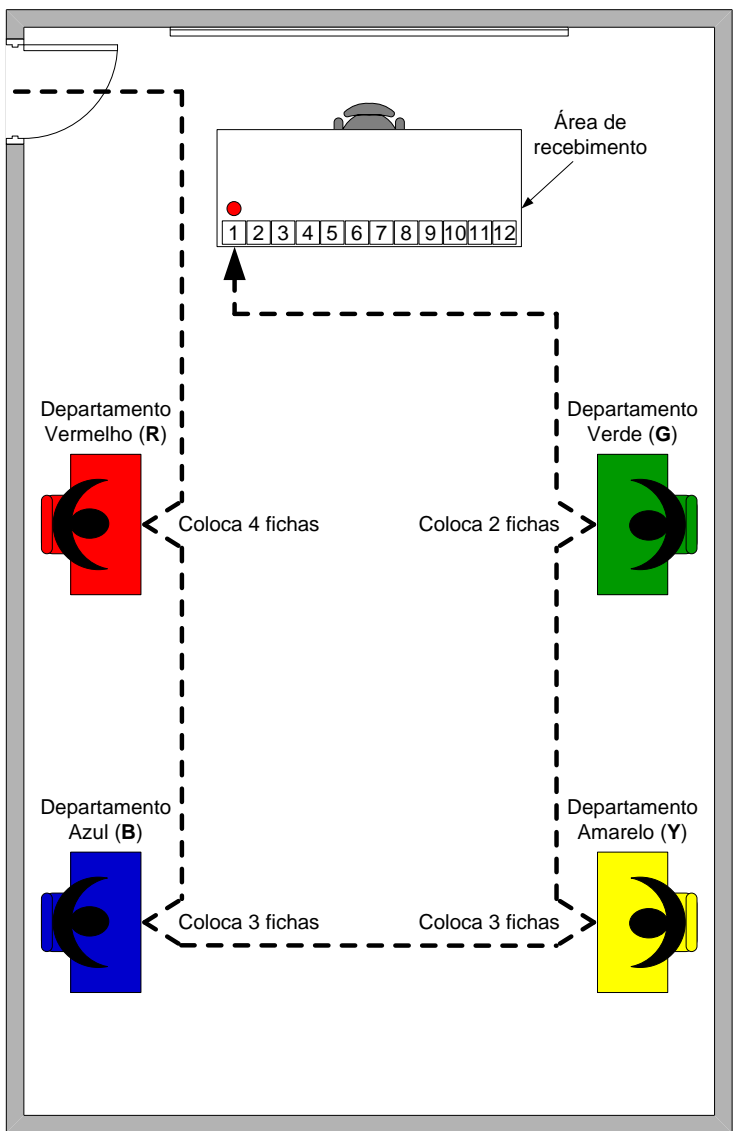

Fonte: Elaborado pelo autores

\section{RESULTADOS E DISCUSSÃO}

Como foi mencionado anteriormente, a dinâmica foi aplicada em duas turmas da disciplina "Sistemas de Produção" de um curso de graduação em Engenharia de Produção. Coincidentemente, em cada uma das duas turmas havia 16 alunos presentes, oportunizando a realização das aplicações sem que fossem necessários revezamentos ou repetições de funções para que todos participassem. Nas duas aplicações o professor exerceu as funções de gerente de PCP e de cronometrista.

Uma situação digna de nota é que em uma das aplicações o makespan do Cenário 2 foi menor que o do Cenário 1, contrariando o comportamento esperado. Ao invés desse evento comprometer a aplicação, ele deu margem para novas discussões. Como o Cenário 3 tinha sido executado antes do 2, foi levantada a possibilidade de ter havido o efeito da curva de aprendizagem, dado que todos já Revista Produção Online, Florianópolis, SC, v.14, n. 3, p. 1129-1150, jul./set. 2014. 
tinham se adaptado à função. Também foi levada em consideração a escala de produção, já que os 12 produtos representavam uma amostra muito pequena quando comparada a um sistema de produção real. Além disso, foi dada ênfase na análise horizontal dos makespans (conforme sugerido na seção anterior), uma vez que nessa comparação foram obtidos resultados coerentes com a matriz produtoprocesso.

Após cada uma das duas aplicações, foi distribuído um questionário com o objetivo de obter um feedback da atividade. Anônimos, os questionários eram compostos por quatro perguntas simples:

- Aprendizagem: A sua participação na dinâmica facilitou a sua aprendizagem dos conceitos teóricos da disciplina?

- Motivação e envolvimento: A aplicação da dinâmica de aprendizagem tornou a aula mais interessante e lhe motivou a participar mais da disciplina?

- Percepção da prática: A dinâmica de aprendizagem permitiu que você pudesse identificar com mais facilidade esses dois tipos de processos em situações reais?

- Importância e continuidade: Você acha fundamental que esta dinâmica seja sempre utilizada na disciplina de Sistemas de Produção?

A tabulação das respostas é apresentada na Tabela 1.

Tabela 1 - Respostas dos questionários de avaliação

\begin{tabular}{|c|c|c|c|c|c|c|}
\hline \multirow[b]{2}{*}{ Itens avaliados } & \multicolumn{5}{|c|}{ Quantidade e percentual de respostas } & \multirow[b]{2}{*}{$\begin{array}{l}\text { Total de } \\
\text { respondentes }\end{array}$} \\
\hline & $\begin{array}{l}\text { Concordo } \\
\text { totalmente }\end{array}$ & Concordo & $\begin{array}{c}\text { Não } \\
\text { concordo } \\
\text { nem } \\
\text { discordo }\end{array}$ & Discordo & $\begin{array}{l}\text { Discordo } \\
\text { totalmente }\end{array}$ & \\
\hline Aprendizagem & $\begin{array}{c}22 \\
(68,8 \%)\end{array}$ & $\begin{array}{c}10 \\
(31,2 \%)\end{array}$ & - & - & - & 32 \\
\hline $\begin{array}{l}\text { Motivação e } \\
\text { envolvimento }\end{array}$ & $\begin{array}{c}19 \\
(59,4 \%)\end{array}$ & $\begin{array}{c}12 \\
(37,5 \%)\end{array}$ & $1(3,1 \%)$ & - & - & 32 \\
\hline Percepção da prática & $\begin{array}{c}24 \\
(75,0 \%)\end{array}$ & $8(25,0 \%)$ & - & - & - & 32 \\
\hline $\begin{array}{l}\text { Importância e } \\
\text { continuidade }\end{array}$ & $\begin{array}{c}25 \\
(78,1 \%)\end{array}$ & $6(18,8 \%)$ & $1(3,1 \%)$ & - & - & 32 \\
\hline
\end{tabular}

Fonte: Elaborado pelos autores 
Como se pode observar na Tabela 1, a dinâmica teve uma excelente aceitação por parte dos alunos. Analisando qualitativamente os efeitos da aplicação, o professor percebeu um aumento significativo da motivação nos estudantes, que passaram a participar mais da aulas após o seu envolvimento em uma atividade de aprendizagem ativa.

De acordo com a classificação de Snider e Balakrishnan (2013), a atividade apresentada se enquadra como uma dinâmica de aprendizagem ativa, na forma experiencial semiestruturada (ver figura 1). Neste caso, os estudantes passam por um processo de experimentação com regras bem definidas e executam uma atividade simples que pode ser inserida no contexto da aula regular.

Do ponto de vista das dimensões do processo de ensino destacadas por Auster e Wylie (2006), é possível comparar a abordagem tradicional, em que o tópico da matriz produto-processo é apresentado em uma aula expositiva, com a abordagem experiencial, na qual os mesmos conceitos são vivenciados por meio da dinâmica relatada aqui. O quadro 2 apresenta esta comparação e se apoia na análise que foi realizada por Santos, Gohr e Vieira Junior (2012) ao discutir os resultados de outra atividade de aprendizagem ativa.

Quadro 2 - Comparação entre duas abordagens para o ensino da matriz produto-processo

\begin{tabular}{|c|c|c|}
\hline $\begin{array}{l}\text { Dimensões do } \\
\text { processo de ensino }\end{array}$ & Abordagem experiencial & Abordagem tradicional \\
\hline Definição do contexto & $\begin{array}{l}\text { O ambiente físico é organizado } \\
\text { como uma fábrica. A interação entre } \\
\text { os pares é encorajada. }\end{array}$ & $\begin{array}{l}\text { O ambiente físico é a sala de aula } \\
\text { em seu formato tradicional. A } \\
\text { interação entre os pares é } \\
\text { desencorajada. }\end{array}$ \\
\hline Preparação da aula & $\begin{array}{l}\text { O professor se prepara para simular } \\
\text { uma fábrica e conduzir o processo } \\
\text { produtivo. }\end{array}$ & $\begin{array}{l}\text { O professor se prepara para } \\
\text { contar "estórias". }\end{array}$ \\
\hline "Entrega" da aula & $\begin{array}{l}\text { Diferentes modos de entrega } \\
\text { (simulação, role-playing) permitem } \\
\text { explorar diferentes estilos de } \\
\text { aprendizagem. }\end{array}$ & Professor fala, alunos escutam. \\
\hline Melhoria contínua & $\begin{array}{l}\text { O feedback dos estudantes é } \\
\text { imediato, o que proporciona a } \\
\text { melhoria da atividade a cada } \\
\text { aplicação. }\end{array}$ & $\begin{array}{l}\text { O feedback dos estudantes } \\
\text { geralmente é recebido ao final da } \\
\text { disciplina, após os exames finais. }\end{array}$ \\
\hline
\end{tabular}

Fonte: Adaptado de Santos, Gohr e Vieira Junior (2012)

Embora a aprendizagem dos conceitos da matriz produto-processo tenha se mostrado mais eficaz com o uso da dinâmica, quando comparada com a aula puramente expositiva, ela não dispensa a abordagem teórica do assunto feita antes

Revista Produção Online, Florianópolis, SC, v.14, n. 3, p. 1129-1150, jul./set. 2014. 
de sua aplicação. Isso ressalta novamente o papel do professor na condução da disciplina e na integração de conceitos teóricos com sua experimentação prática.

\section{CONSIDERAÇÕES FINAIS}

Este artigo descreveu uma dinâmica de ensino utilizada para compreensão da matriz produto-processo, um modelo para classificação de sistemas de produção e análise do alinhamento dos mesmos com diferentes estruturas de produtos. A dinâmica seguiu a filosofia da aprendizagem ativa, estimulando os estudantes a experimentarem situações que permitiam auxiliá-los a consolidar conceitos teóricos e a construir seu próprio conhecimento.

Embora uma versão anterior da dinâmica já tenha sido publicada por Penlesky e Treleven (2005), este artigo contribuiu com adaptações feitas à proposta inicial e com um maior detalhamento de sua aplicação, trazendo um roteiro que pode ser seguido facilmente por outros professores ou por instrutores de cursos de treinamento na área.

As respostas do questionário de avaliação, aplicado logo após a realização da dinâmica, confirmaram a ampla aceitação que a mesma teve entre os estudantes. Como efeito dessa aceitação, foi observada uma maior motivação nas aulas posteriores à aplicação. Ao comparar os participantes com os alunos de turmas de semestres anteriores, que não participaram da atividade, observou-se uma compreensão maior do assunto que foi objeto da atividade (matriz produtoprocesso).

A continuidade deste trabalho poderá acontecer com o aperfeiçoamento da dinâmica para a montagem de produtos mais complexos. Por outro lado, a simplicidade de seu procedimento pode ser considerada uma vantagem dessa atividade didática, uma vez que a mesma pode ser realizada facilmente em vinte ou trinta minutos.

Considerando a vantagem da simplicidade no uso de fichas coloridas de plástico armazenadas em tubos de PVC, outro caminho para continuidade deste trabalho está no uso deste mesmo material para a aprendizagem de outros conceitos de gestão da produção que demandam a simulação do fluxo de processos.

Revista Produção Online, Florianópolis, SC, v.14, n. 3, p. 1129-1150, jul./set. 2014. 


\section{REFERÊNCIAS}

AHMAD, S.; SCHROEDER, R. G. Refining the product-process matrix. International Journal of Operations \& Production Management, v. 22, n. 1, p. 103-124, 2002. http://dx.doi.org/10.1108/01443570210412097

AMMAR, S.; WRIGHT, R. Experiential learning activities in operations management. International Transactions in Operational Research, v. 6, n. 2, p. 183-197, 1999. http://dx.doi.org/10.1111/j.1475-3995.1999.tb00150.x

AUSTER, E. R.; WYLIE, K. K. Creating active learning in the classroom: a systematic approach. Journal of Management Education, v. 30, n. 2, p. 333-353, 2006. http://dx.doi.org/10.1177/1052562905283346

BILLINGTON, P. J. A classroom exercise to illustrate lean manufacturing pull concepts. Decision Sciences Journal of Innovative Education, v. 2, n. 1, p. 71-76, 2004. http://dx.doi.org/10.1111/j.0011-7315.2004.00021.x

BONWELL, C. C.; EISON, J. A. Active learning: creating excitement in the classroom (ASHE-ERIC Higher Education Report No. 1), George Washington University, Washington, DC, 1991.

CÓ, F. A.; CÓ, M. A.; MERIGUETI, B. A. O "heyjunka didático": um jogo interdisciplinar que auxilia na elevação da aprendizagem sobre a produção enxuta. In: ENCONTRO NACIONAL DE ENGENHARIA DE PRODUÇÃO, 28, 2008, Rio de Janeiro - RJ. Anais... Rio de Janeiro: ABEPRO, 2008. CD-ROM.

HAYES, R. H.; WHEELWRIGHT, S. C. Link manufacturing process and product life cycles. Harvard Business Review, v. 57, n. 1, p. 133-140, 1979.

HELKIÖ, P.; TENHIÄLÄ, A. A contingency theoretical perspective to the productprocess matrix. International Journal of Operations \& Production Management, v. 33, n. 2, p. 216-244, 2013.

http://dx.doi.org/10.1108/01443571311295644

HERIOT, K. C. et al. The use of student consulting projects as an active learning pedagogy: a case study in a Production/Operations Management course. Decision Sciences Journal of Innovative Education, v. 6, n. 2, p. 463-481, 2008. http://dx.doi.org/10.1111/j.1540-4609.2008.00186.x

HILL, T. Manufacturing strategy: text and cases. 2.ed. Burr Ridge: Irwin, 1994.

ITIN, C. M.. Reasserting the philosophy of experiential education as a vehicle for change in the 21st century. Journal of Experiential Education, v. 22, n. 2, p. 91-98, 1999. http://dx.doi.org/10.1177/105382599902200206

KRAJEWSKY, L.; RITZMAN, L.; MALHOTRA, M. Administração de produção e operações. 8.ed. São Paulo: Prentice Hall, 2009.

Revista Produção Online, Florianópolis, SC, v.14, n. 3, p. 1129-1150, jul./set. 2014. 
LAGE JUNIOR, M. Proposição de um jogo didático para o ensino-aprendizagem das diferenças entre manufatura e remanufatura. In: ENCONTRO NACIONAL DE ENGENHARIA DE PRODUÇÃO, 28, 2008, Rio de Janeiro - RJ. Anais... Rio de Janeiro: ABEPRO, 2008. CD-ROM.

LAMBRECHT, M. et al. Extending the production dice game. International Journal of Operations \& Production Management, v. 32, n. 12, p. 1460 - 1472, 2012. http://dx.doi.org/10.1108/01443571211284197

OZELKAN, E.; GALAMBOSI, A. Lampshade game for lean manufacturing.

Production Planning \& Control, v. 20, n. 5, p. 385-402, 2009.

http://dx.doi.org/10.1080/09537280902875419

PENLESKY, R. J.; TRELEVEN, M. D. The product-process matrix brought to life. Decision Sciences Journal of Innovative Education, v. 3, n. 2, p. 347-355, 2005. http://dx.doi.org/10.1111/j.1540-4609.2005.00076.x

PRINCE, M. Does active learning work? A review of the research. Journal of Engineering Education, v. 93, n. 3, p. 223-231, 2004.

http://dx.doi.org/10.1002/j.2168-9830.2004.tb00809.x

SANTOS, L. C.; GOHR, C. F.; VIEIRA JUNIOR, M. Simulation of assembly operations using interchangeable parts for OM education: a hands-on activity with water pipe fittings. International Journal of Operations \& Production Management, v. 32, n. 12, p. 1427-1440, 2012. http://dx.doi.org/10.1108/01443571211284179

SLACK, N.; CHAMBERS, S.; JOHNSTON, R. Administração da produção. 2.ed. São Paulo: Atlas, 2002.

SMEDS, R. Guest editorial: Simulation for accelerated learning and development in industrial management. Production Planning \& Control, v. 14, n. 2, p. 107-110, 2003. http://dx.doi.org/10.1080/0953728031000107707

SNIDER, B.; BALAKRISHNAN, J. Lessons learned from implementing web-based simulations to teach operations management concepts. INFORMS Transactions on Education, v. 13, n. 3, p. 152-161, 2013. http://dx.doi.org/10.1287/ited.2013.0108

ZEPKE, N.; LEACH, L. Improving student engagement: ten proposals for action. Active Learning in Higher Education, v. 11, n. 3, p. 167-177, 2010. http://dx.doi.org/10.1177/1469787410379680

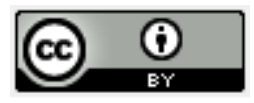

Artigo recebido em 17/11/2013 e aceito para publicação em 15/04/2014

DOI: http://dx.doi.org/ 10.14488/1676-1901.v14i3.1700 


\section{ANEXO I: Roteiros de produção para produtos PERSONALIZADOS}

\begin{tabular}{|c|c|c|}
\hline \multicolumn{3}{|c|}{ Produtos Personalizados } \\
\hline \multicolumn{3}{|c|}{ TAREFA 1 } \\
\hline Sequência & $\begin{array}{c}\text { Processo/ } \\
\text { peça }\end{array}$ & $\begin{array}{c}\text { Quant./ } \\
\text { montagem }\end{array}$ \\
\hline 1 & $\mathrm{R}$ & 3 \\
\hline 2 & $\mathrm{Y}$ & 6 \\
\hline & & \\
\hline & & \\
\hline
\end{tabular}

\begin{tabular}{|c|c|c|}
\hline \multicolumn{3}{|c|}{ Produtos Personalizados } \\
\hline \multicolumn{3}{|c|}{ TAREFA 4 } \\
\hline Sequência & $\begin{array}{c}\text { Processo/ } \\
\text { peça }\end{array}$ & $\begin{array}{c}\text { Quant./ } \\
\text { montagem }\end{array}$ \\
\hline 1 & $\mathrm{R}$ & 4 \\
\hline 2 & $\mathrm{G}$ & 1 \\
\hline 3 & $\mathrm{Y}$ & 2 \\
\hline & & \\
\hline
\end{tabular}

\begin{tabular}{|c|c|c|}
\hline \multicolumn{3}{|c|}{ Produtos Personalizados } \\
\hline \multicolumn{3}{|c|}{ TAREFA 7 } \\
\hline Sequência & $\begin{array}{c}\text { Processo/ } \\
\text { peça }\end{array}$ & $\begin{array}{c}\text { Quant./ } \\
\text { montagem }\end{array}$ \\
\hline 1 & $\mathrm{Y}$ & 4 \\
\hline 2 & $\mathrm{R}$ & 3 \\
\hline 3 & $\mathrm{~B}$ & 2 \\
\hline 4 & $\mathrm{G}$ & 1 \\
\hline
\end{tabular}

\begin{tabular}{|c|c|c|}
\hline \multicolumn{3}{|c|}{ Produtos Personalizados } \\
\hline \multicolumn{3}{|c|}{ TAREFA 10 } \\
\hline Sequência & $\begin{array}{c}\text { Processo/ } \\
\text { peça }\end{array}$ & $\begin{array}{c}\text { Quant./ } \\
\text { montagem }\end{array}$ \\
\hline 1 & $\mathrm{G}$ & 2 \\
\hline 2 & $\mathrm{Y}$ & 5 \\
\hline 3 & $\mathrm{~B}$ & 10 \\
\hline & & \\
\hline
\end{tabular}

\begin{tabular}{|c|c|c|}
\hline \multicolumn{3}{|c|}{ Produtos Personalizados } \\
\hline \multicolumn{3}{|c|}{ TAREFA 2 } \\
\hline Sequência & $\begin{array}{c}\text { Processo/ } \\
\text { peça }\end{array}$ & $\begin{array}{c}\text { Quant./ } \\
\text { montagem }\end{array}$ \\
\hline 1 & $\mathrm{R}$ & 5 \\
\hline 2 & $\mathrm{Y}$ & 1 \\
\hline 3 & $\mathrm{G}$ & 1 \\
\hline 4 & $\mathrm{~B}$ & 3 \\
\hline
\end{tabular}

\begin{tabular}{|c|c|c|}
\hline \multicolumn{3}{|c|}{ Produtos Personalizados } \\
\hline \multicolumn{3}{|c|}{ TAREFA 5 } \\
\hline Sequência & $\begin{array}{c}\text { Processo/ } \\
\text { peça }\end{array}$ & $\begin{array}{c}\text { Quant./ } \\
\text { montagem }\end{array}$ \\
\hline 1 & $\mathrm{~B}$ & 3 \\
\hline 2 & $\mathrm{R}$ & 5 \\
\hline 3 & $\mathrm{G}$ & 8 \\
\hline & & \\
\hline
\end{tabular}

\begin{tabular}{|c|c|c|}
\hline \multicolumn{3}{|c|}{ Produtos Personalizados } \\
\hline \multicolumn{3}{|c|}{ TAREFA 8 } \\
\hline Sequência & $\begin{array}{c}\text { Processo/ } \\
\text { peça }\end{array}$ & $\begin{array}{c}\text { Quant./ } \\
\text { montagem }\end{array}$ \\
\hline 1 & $\mathrm{~B}$ & 4 \\
\hline 2 & $\mathrm{G}$ & 4 \\
\hline 3 & $\mathrm{R}$ & 8 \\
\hline & & \\
\hline
\end{tabular}

\begin{tabular}{|c|c|c|}
\hline \multicolumn{3}{|c|}{ Produtos Personalizados } \\
\hline \multicolumn{3}{|c|}{ TAREFA 11 } \\
\hline Sequência & $\begin{array}{c}\text { Processo/ } \\
\text { peça }\end{array}$ & $\begin{array}{c}\text { Quant./ } \\
\text { montagem }\end{array}$ \\
\hline 1 & $\mathrm{G}$ & 3 \\
\hline 2 & $\mathrm{~B}$ & 3 \\
\hline 3 & $\mathrm{R}$ & 8 \\
\hline & & \\
\hline
\end{tabular}

\begin{tabular}{|c|c|c|}
\hline \multicolumn{3}{|c|}{ Produtos Personalizados } \\
\hline \multicolumn{3}{|c|}{ TAREFA 3 } \\
\hline Sequência & $\begin{array}{c}\text { Processo/ } \\
\text { peça }\end{array}$ & $\begin{array}{c}\text { Quant./ } \\
\text { montagem }\end{array}$ \\
\hline 1 & G & 1 \\
\hline 2 & B & 5 \\
\hline 3 & Y & 9 \\
\hline & & \\
\hline
\end{tabular}

\begin{tabular}{|c|c|c|}
\hline \multicolumn{3}{|c|}{ Produtos Personalizados } \\
\hline \multicolumn{3}{|c|}{ TAREFA 6 } \\
\hline Sequência & $\begin{array}{c}\text { Processo/ } \\
\text { peça }\end{array}$ & $\begin{array}{c}\text { Quant./ } \\
\text { montagem }\end{array}$ \\
\hline 1 & B & 2 \\
\hline 2 & G & 3 \\
\hline 3 & Y & 4 \\
\hline & & \\
\hline
\end{tabular}

\begin{tabular}{|c|c|c|}
\hline \multicolumn{3}{|c|}{ Produtos Personalizados } \\
\hline \multicolumn{3}{|c|}{ TAREFA 9 } \\
\hline Sequência & $\begin{array}{c}\text { Processo/ } \\
\text { peça }\end{array}$ & $\begin{array}{c}\text { Quant./ } \\
\text { montagem }\end{array}$ \\
\hline 1 & $\mathrm{Y}$ & 1 \\
\hline 2 & $\mathrm{R}$ & 8 \\
\hline & & \\
\hline & & \\
\hline
\end{tabular}

\begin{tabular}{|c|c|c|}
\hline \multicolumn{3}{|c|}{ Produtos Personalizados } \\
\hline \multicolumn{3}{|c|}{ TAREFA 12 } \\
\hline Sequência & $\begin{array}{c}\text { Processo/ } \\
\text { peça }\end{array}$ & $\begin{array}{c}\text { Quant./ } \\
\text { montagem }\end{array}$ \\
\hline 1 & $\mathrm{Y}$ & 4 \\
\hline 2 & $\mathrm{~B}$ & 4 \\
\hline 3 & $\mathrm{R}$ & 4 \\
\hline & & \\
\hline
\end{tabular}

Legenda:

\begin{tabular}{ll}
\hline Depto. Amarelo & $\mathrm{Y}($ yellow) \\
\hline Depto. Azul & $\mathrm{B}($ blue $)$ \\
\hline Depto. Verde & $\mathrm{G}($ green $)$ \\
\hline Depto. Vermelho & $\mathrm{R}($ red $)$ \\
\hline
\end{tabular}

Revista Produção Online, Florianópolis, SC, v.14, n. 3, p. 1129-1150, jul./set. 2014. 


\section{ANEXO II: Roteiros de produção para produtos PADRONIZADOS}

\begin{tabular}{|c|c|c|}
\hline \multicolumn{3}{|c|}{ Produtos Padronizados } \\
\hline \multicolumn{3}{|c|}{ TAREFA 1 } \\
\hline Sequência & $\begin{array}{c}\text { Processo/ } \\
\text { peça }\end{array}$ & $\begin{array}{c}\text { Quant./ } \\
\text { montagem }\end{array}$ \\
\hline 1 & $\mathrm{R}$ & 4 \\
\hline 2 & $\mathrm{~B}$ & 3 \\
\hline 3 & $\mathrm{G}$ & 3 \\
\hline 4 & $\mathrm{Y}$ & 2 \\
\hline
\end{tabular}

\begin{tabular}{|c|c|c|}
\hline \multicolumn{3}{|c|}{ Produtos Padronizados } \\
\hline \multicolumn{3}{|c|}{ TAREFA 4 } \\
\hline Sequência & $\begin{array}{c}\text { Processo/ } \\
\text { peça }\end{array}$ & $\begin{array}{c}\text { Quant./ } \\
\text { montagem }\end{array}$ \\
\hline 1 & $\mathrm{R}$ & 4 \\
\hline 2 & $\mathrm{~B}$ & 3 \\
\hline 3 & $\mathrm{G}$ & 3 \\
\hline 4 & $\mathrm{Y}$ & 2 \\
\hline
\end{tabular}

\begin{tabular}{|c|c|c|}
\hline \multicolumn{3}{|c|}{ Produtos Padronizados } \\
\hline \multicolumn{3}{|c|}{ TAREFA 7 } \\
\hline Sequência & $\begin{array}{c}\text { Processo/ } \\
\text { peça }\end{array}$ & $\begin{array}{c}\text { Quant./ } \\
\text { montagem }\end{array}$ \\
\hline 1 & $\mathrm{R}$ & 4 \\
\hline 2 & $\mathrm{~B}$ & 3 \\
\hline 3 & $\mathrm{G}$ & 3 \\
\hline 4 & $\mathrm{Y}$ & 2 \\
\hline
\end{tabular}

\begin{tabular}{|c|c|c|}
\hline \multicolumn{3}{|c|}{ Produtos Padronizados } \\
\cline { 2 - 3 } TAREFA 10 \\
\hline Sequência & $\begin{array}{c}\text { Processo/ } \\
\text { peça }\end{array}$ & $\begin{array}{c}\text { Quant./ } \\
\text { montagem }\end{array}$ \\
\hline 1 & $\mathrm{R}$ & 4 \\
\hline 2 & $\mathrm{~B}$ & 3 \\
\hline 3 & $\mathrm{G}$ & 3 \\
\hline 4 & $\mathrm{Y}$ & 2 \\
\hline
\end{tabular}

\begin{tabular}{|c|c|c|}
\hline \multicolumn{3}{|c|}{ Produtos Padronizados } \\
\hline \multicolumn{3}{|c|}{ TAREFA 2 } \\
\hline Sequência & $\begin{array}{c}\text { Processo/ } \\
\text { peça }\end{array}$ & $\begin{array}{c}\text { Quant./ } \\
\text { montagem }\end{array}$ \\
\hline 1 & $\mathrm{R}$ & 4 \\
\hline 2 & $\mathrm{~B}$ & 3 \\
\hline 3 & $\mathrm{G}$ & 3 \\
\hline 4 & $\mathrm{Y}$ & 2 \\
\hline
\end{tabular}

\begin{tabular}{|c|c|c|}
\hline \multicolumn{3}{|c|}{ Produtos Padronizados } \\
\hline \multicolumn{3}{|c|}{ TAREFA 5 } \\
\hline Sequência & $\begin{array}{c}\text { Processo/ } \\
\text { peça }\end{array}$ & $\begin{array}{c}\text { Quant./ } \\
\text { montagem }\end{array}$ \\
\hline 1 & $\mathrm{R}$ & 4 \\
\hline 2 & $\mathrm{~B}$ & 3 \\
\hline 3 & $\mathrm{G}$ & 3 \\
\hline 4 & $\mathrm{Y}$ & 2 \\
\hline
\end{tabular}

\begin{tabular}{|c|c|c|}
\hline \multicolumn{3}{|c|}{ Produtos Padronizados } \\
\hline \multicolumn{3}{|c|}{ TAREFA 8 } \\
\hline Sequência & $\begin{array}{c}\text { Processo/ } \\
\text { peça }\end{array}$ & $\begin{array}{c}\text { Quant./ } \\
\text { montagem }\end{array}$ \\
\hline 1 & $\mathrm{R}$ & 4 \\
\hline 2 & $\mathrm{~B}$ & 3 \\
\hline 3 & $\mathrm{G}$ & 3 \\
\hline 4 & $\mathrm{Y}$ & 2 \\
\hline
\end{tabular}

\begin{tabular}{|c|c|c|}
\hline \multicolumn{3}{|c|}{ Produtos Padronizados } \\
\hline \multicolumn{3}{|c|}{ TAREFA 11 } \\
\hline Sequência & $\begin{array}{c}\text { Processo/ } \\
\text { peça }\end{array}$ & $\begin{array}{c}\text { Quant./ } \\
\text { montagem }\end{array}$ \\
\hline 1 & $\mathrm{R}$ & 4 \\
\hline 2 & $\mathrm{~B}$ & 3 \\
\hline 3 & $\mathrm{G}$ & 3 \\
\hline 4 & $\mathrm{Y}$ & 2 \\
\hline
\end{tabular}

\begin{tabular}{|c|c|c|}
\hline \multicolumn{3}{|c|}{ Produtos Padronizados } \\
\hline \multicolumn{3}{|c|}{ TAREFA 3 } \\
\hline Sequência & $\begin{array}{c}\text { Processo/ } \\
\text { peça }\end{array}$ & $\begin{array}{c}\text { Quant./ } \\
\text { montagem }\end{array}$ \\
\hline 1 & $\mathrm{R}$ & 4 \\
\hline 2 & $\mathrm{~B}$ & 3 \\
\hline 3 & $\mathrm{G}$ & 3 \\
\hline 4 & $\mathrm{Y}$ & 2 \\
\hline
\end{tabular}

\begin{tabular}{|c|c|c|}
\hline \multicolumn{3}{|c|}{ Produtos Padronizados } \\
\hline \multicolumn{3}{|c|}{ TAREFA 6 } \\
\hline Sequência & $\begin{array}{c}\text { Processo/ } \\
\text { peça }\end{array}$ & $\begin{array}{c}\text { Quant./ } \\
\text { montagem }\end{array}$ \\
\hline 1 & $\mathrm{R}$ & 4 \\
\hline 2 & $\mathrm{~B}$ & 3 \\
\hline 3 & $\mathrm{G}$ & 3 \\
\hline 4 & $\mathrm{Y}$ & 2 \\
\hline
\end{tabular}

\begin{tabular}{|c|c|c|}
\hline \multicolumn{3}{|c|}{ Produtos Padronizados } \\
\hline \multicolumn{3}{|c|}{ TAREFA 9 } \\
\hline Sequência & $\begin{array}{c}\text { Processo/ } \\
\text { peça }\end{array}$ & $\begin{array}{c}\text { Quant./ } \\
\text { montagem }\end{array}$ \\
\hline 1 & $\mathrm{R}$ & 4 \\
\hline 2 & $\mathrm{~B}$ & 3 \\
\hline 3 & $\mathrm{G}$ & 3 \\
\hline 4 & $\mathrm{Y}$ & 2 \\
\hline
\end{tabular}

\begin{tabular}{|c|c|c|}
\hline \multicolumn{3}{|c|}{ Produtos Padronizados } \\
\hline \multicolumn{3}{|c|}{ TAREFA 12 } \\
\hline Sequência & $\begin{array}{c}\text { Processo/ } \\
\text { peça }\end{array}$ & $\begin{array}{c}\text { Quant./ } \\
\text { montagem }\end{array}$ \\
\hline 1 & $\mathrm{R}$ & 4 \\
\hline 2 & $\mathrm{~B}$ & 3 \\
\hline 3 & $\mathrm{G}$ & 3 \\
\hline 4 & $\mathrm{Y}$ & 2 \\
\hline
\end{tabular}

Legenda:

\begin{tabular}{ll}
\hline Depto. Amarelo & $\mathrm{Y}($ yellow $)$ \\
\hline Depto. Azul & $\mathrm{B}($ blue $)$ \\
\hline Depto. Verde & $\mathrm{G}($ green $)$ \\
\hline Depto. Vermelho & $\mathrm{R}($ red $)$ \\
\hline
\end{tabular}

Revista Produção Online, Florianópolis, SC, v.14, n. 3, p. 1129-1150, jul./set. 2014. 